\title{
Projeção do diâmetro e altura de árvores em uma floresta estacional semidecidual por meio de redes neurais artificiais
}

\author{
Projection of the trees diameter and height in a semideciduous forest by \\ artificial neural networks
}

\author{
Renato Vinícius Oliveira Castro ${ }^{1}$ (D), Carlos Pedro Boechat Soares ${ }^{2}$ (D), Helio Garcia Leite ${ }^{2}$ (1), \\ Agostinho Lopes de Souza ${ }^{2}$ (D), Fabrina Bolzan Martins ${ }^{3}$ (1) , Gilciano Saraiva Nogueira ${ }^{4}$ (1), \\ Márcio Leles Romarco de Oliveira ${ }^{4}$ (i) \\ ${ }^{1}$ Universidade Federal de São João del-Rei - UFSJ, Sete Lagoas, MG, Brasil \\ ${ }^{2}$ Universidade Federal de Viçosa - UFV, Viçosa, MG, Brasil \\ ${ }^{3}$ Universidade Federal de Itajubá - UNIFEI, Itajubá, MG, Brasil \\ ${ }^{4}$ Universidade Federal dos Vales do Jequitinhonha e Mucuri - UFVJM, Diamantina, MG, Brasil
}

Como citar: Castro, R. V. O., Soares, C. P. B., Leite, H. G., Souza, A. L., Martins, F. B., Nogueira, G. S., \& Oliveira, M. L. R. (2020). Projeção do diâmetro e altura de árvores em uma floresta estacional semidecidual por meio de redes neurais artificiais. Scientia Forestalis, 48(125), e3056. https://doi.org/10.18671/scifor.v48n125.18

\begin{abstract}
Resumo
Este estudo teve como objetivo avaliar a eficiência de redes neurais artificiais para projetar o diâmetro (dap), altura total $(H t)$ e altura do fuste $(H f)$ de árvores em uma Floresta Estacional Semidecidual em estágio médio de sucessão. Foram utilizados dados de dez parcelas permanentes, monitoradas durante de 14 anos, em cinco ocasiões, localizadas no município de Viçosa, Minas Gerais. O conjunto de dados foi dividido aleatoriamente em dois grupos: grupo de treinamento, composto por seis parcelas, totalizando nas cinco medições, 3.556 casos, e o grupo de generalização, composto por quatro parcelas, as quais foram utilizadas para avaliar o poder de generalização das redes após o treinamento, totalizando 2.062 casos. Redes neurais foram treinadas e aplicadas para projetar simultaneamente o dap, $H t$ e $H f$, utilizando diferentes arquiteturas, modelos de redes (MLP e RBF) e funções de ativação. As variáveis de entrada foram os diâmetros e alturas das árvores observadas numa ocasião presente, índices de competição, nível de iluminação das copas, qualidade da copa, grupo ecológico e família botânica. Foram obtidas redes com alto poder generalista para as três variáveis de saída simultaneamente ( $d a p$, $H t$ e $H f$ ). Os resultados encontrados confirmam o potencial de utilização de redes neurais para a projeção do crescimento de árvores em Floresta Estacional Semidecidual Montana.
\end{abstract}

Palavras chaves: Floresta Natural Semidecidual Montana; Floresta inequiânea; Crescimento de árvore individual.

\begin{abstract}
This study aimed to evaluate the efficiency of artificial neural networks to design the diameter $(d b h)$, total height $(H t)$ and bole height $(H f)$ of trees in a semideciduous forest in the middle succession stage. Were used data from ten permanent plots, monitored for 14 years, on five occasions, located in Viçosa, Minas Gerais. The data set was randomly divided into two groups: training group, consisting of six plots, totaling at the five measurements 3,556 cases and generalization group, composed by four plots, which were used to evaluate the generalization networks power after training, totaling 2,062 cases. Neural networks were trained and applied to design simultaneously $d b h, H t$ and $H f$ using different architectures, networks models (MLP and RBF) and activation functions. The input variables were the diameter and height of trees observed in a present occasion, competition indexes, crown illumination level, crown quality, ecological and botanical family group. Neural networks were obtained with high power generalist for the three output variables simultaneously ( $d b h, H t$ and $H f$ ). The results confirm the potential of using neural networks to the trees growth projection in a Semideciduous Montana Forest.
\end{abstract}

Keywords: Semidecidual Montana Forest; Uneven-age forest; Individual tree growth.

Fonte de financiamento: CNPq (Processos 140334/2011-4 e 300941/2016-1).

Conflito de interesse: Nada a declarar.

Autor correspondente: renatocastro@ufsj.edu.br

Recebido: 16 agosto 2018.

Aceito: 12 junho 2019.

Editor: Francides Gomes da Silva Júnior.

(c) (i) Este é um artigo publicado em acesso aberto (Open Access) sob a licença Creative Commons Attribution, que permite uso, distribuição e reprodução cc. em qualquer meio, sem restrições desde que o trabalho original seja corretamente citado. 


\section{INTRODUÇÃO}

Durante as últimas décadas tem sido um interesse na mensuração florestal o desenvolvimento de modelos de crescimento e produção utilizando árvores individuais (Bella, 1971; Daniels, 1976; Glover \& Hool, 1979; Hasenauer \& Monserud, 1996; Eid \& Tuhus, 2001; Vospernik et al., 2010; Martins, 2011).

A modelagem do crescimento e produção de árvores individuais consiste em estabelecer diferentes sub-modelos para predizerem o crescimento em diâmetro, altura, ingresso e mortalidade (Tomé \& Burkhart, 1989; Hasenauer et al., 1998; Sánchez-González et al., 2006).

Estudos têm sido realizados com o intuito de comparar as melhores funções para predição do crescimento das árvores (Hasenauer \& Monserud, 1996; Andreassen \& Tomter, 2003; Sánchez-González et al., 2006; Vospernik et al., 2010; Martins, 2011). No entanto, existem duas dificuldades principais na definição dos modelos: 1) definir as variáveis explanatórias mais indicadas para serem utilizadas no modelo e 2) a inclusão de variáveis qualitativas nos modelos de regressão.

Nesse sentido, as redes neurais artificiais (RNA) podem ser utilizadas como alternativa ao procedimento tradicional de modelagem em nível de árvore individual (Guan \& Gertner, 1991). As RNA's são aplicadas em problemas de classificação de dados, análise de séries temporais e reconhecimento de padrões (Jain et al., 1996; Haykin, 2001; Barreto, 2002).

Grande número de autores discutiu estrutura, técnica e operação das RNA Jain et al., 1996; Barreto, 2002; Braga et al., 2000). Durante os últimos anos houve maior interesse em utilizar as RNA na ciência florestal (Diamantopoulou, 2005; Miehle et al., 2009; Özçelik et al., 2010; Cunha, 2010) e na estimativa do crescimento e produção de árvores individuais.

Dentre os principais trabalhos sobre crescimento em nível de árvore individual por meio de RNA destacam-se os trabalhos de Porras (2007) que projetou o diâmetro e a altura de Pinus cooperi em uma floresta no México, e Binoti (2010) e Castro (2011) que projetaram o diâmetro e a altura de árvores individuais de Eucalyptus spp. no Brasil. O uso de RNA's em florestas tropicais para modelagem em nível de árvore individual ainda são escassos.

Diante desta lacuna, o presente estudo teve como objetivo avaliar a eficiência de redes neurais para projetar o diâmetro e altura de árvores em um fragmento de Floresta Estacional Semidecidual em estágio médio de sucessão, no município de Viçosa, MG.

\section{MATERIAL E MÉTODOS}

\section{Dados}

Os dados utilizados neste estudo foram obtidos no município de Viçosa, Minas Gerais, em um fragmento florestal pertencente à Universidade Federal de Viçosa, que possui 17 ha de área $\left(42^{\circ} 52^{\prime} \mathrm{W}\right.$ e $42^{\circ} 50^{\prime} \mathrm{W}$ de longitude e $20^{\circ} 44^{\prime} \mathrm{S}$ e $20^{\circ} 47^{\prime} \mathrm{S}$ de latitude), pertencente à região fitoecológica de Floresta Estacional Semidecidual Montana, em estágio médio de sucessão.

Para o presente trabalho, foi amostrado um hectare, dividido em dez parcelas retangulares, não contínuas, de $1.000 \mathrm{~m}^{2}$ cada $(20 \mathrm{~m} \times 50 \mathrm{~m})$. Em cada parcela, foram identificadas as árvores e mensurados os diâmetros a 1,3 $\mathrm{m}$ de altura (dap), as alturas total $(H t)$ e do fuste $(H f)$ de todas as árvores com dap $\geq 5 \mathrm{~cm}$. Para cada árvore foram determinadas as coordenas $x$ e $y$ em relação à origem da sua parcela, para criação de um mapa de localização dos indivíduos e estimação dos índices de competição. Os inventários foram realizados nos anos 1994, 1997, 2000, 2004 e 2008.

Os indivíduos mensurados foram classificados em relação aos níveis de infestação por cipós, iluminação de copa e qualidade de copa, conforme algumas das variáveis qualitativas propostas por Silva \& Lopes (1984), além de serem classificados em grupos ecológicos (Gandolfi et al., 1995) (Tabela 1): 
Tabela 1: Classificação dos indivíduos em relação aos níveis de infestação por cipós, iluminação de copa e qualidade de copa e grupos ecológicos.

\begin{tabular}{|c|c|}
\hline \multicolumn{2}{|l|}{ Critérios para classificação } \\
\hline \multicolumn{2}{|l|}{ Infestação por Cipós } \\
\hline Sem presença de cipós & [1] \\
\hline Presença de cipós somente no fuste & {$[2]$} \\
\hline Presença de cipós somente na copa & [3] \\
\hline Presença de cipós no fuste e na copa & [4] \\
\hline \multicolumn{2}{|l|}{ Iluminação de copa } \\
\hline Copa recebendo radiação solar direta na sua parte superior e lateral & [1] \\
\hline Copa recebendo radiação solar direta na sua parte superior & {$[2]$} \\
\hline Ausência de radiação solar direta na copa & [3] \\
\hline \multicolumn{2}{|l|}{ Qualidade da copa } \\
\hline Boa: copa normal, sem presença de danos & [1] \\
\hline Regular: copa com algum dano de pequena escala & [2] \\
\hline Inferior: copa com severos danos, com poucos galhos e folhas & [3] \\
\hline \multicolumn{2}{|l|}{ Grupo Ecológico } \\
\hline $\begin{array}{l}\text { Espécies dependentes de luz e que não ocorrem no sub- bosque, se } \\
\text { desenvolvendo em clareiras ou bordas da floresta }\end{array}$ & [Pioneiras (PI)] \\
\hline $\begin{array}{l}\text { Desenvolvem-se em condições de sombreamento médio, como pequenas } \\
\text { clareiras e sub-bosque não densamente sombreado }\end{array}$ & [Secundárias iniciais (SI)] \\
\hline $\begin{array}{l}\text { Desenvolvem-se no sub-bosque em condições de sombra leve ou densa, } \\
\text { podendo crescer até alcançar o dossel }\end{array}$ & [Secundárias tardias (ST)] \\
\hline $\begin{array}{l}\text { Espécies que em função da carência de informações não foram incluídas em } \\
\text { nenhuma das categorias }\end{array}$ & [Sem classificação (SC)] \\
\hline
\end{tabular}

Para o entendimento do possível efeito dessas variáveis nas taxas de crescimento das árvores, foram elaborados gráficos de barras para as taxas anuais de crescimento em dap, $\mathrm{Ht}$ e $H f$ em função de cada uma dessas variáveis.

As principais características quantitativas do povoamento estudado são apresentadas na Tabela 2.

Tabela 2. Sumário dos dados do inventário no fragmento de Floresta Estacional Semidecidual Montana, em estágio médio de sucessão, localizado em Viçosa - Minas Gerais

\begin{tabular}{|c|c|c|c|c|c|}
\hline \multirow{2}{*}{ Variável } & \multicolumn{5}{|c|}{ Ano de medição } \\
\hline & 1994 & 1997 & 2000 & 2004 & 2008 \\
\hline dap mínimo (cm) & 5,1 & 5,1 & 5,1 & 5,1 & 5,0 \\
\hline dap médio (cm) & 11,6 & 11,8 & 12,0 & 12,0 & 12,2 \\
\hline dap máximo (cm) & 80,2 & 82,1 & 84,0 & 85,6 & 91,0 \\
\hline$q(\mathrm{~cm})$ & 14,2 & 14,6 & 14,9 & 15,0 & 15,3 \\
\hline Ht mínima (m) & 2,5 & 2,5 & 2,5 & 2,4 & 2,4 \\
\hline Ht média (m) & 10,4 & 11,1 & 11,4 & 12,4 & 12,5 \\
\hline Ht máxima (m) & 32,1 & 32,4 & 33,0 & 39,2 & 39,4 \\
\hline Hf mínima (m) & 1,0 & 1,3 & 1,3 & 1,4 & 1,4 \\
\hline Hf média (m) & 7,0 & 7,3 & 7,5 & 7,5 & 7,9 \\
\hline Hf máxima $(\mathrm{m})$ & 18,7 & 24,0 & 24,0 & 24,0 & 24,0 \\
\hline Área basal $\left(\mathrm{m}^{2} \mathrm{ha}^{-1}\right)$ & 24,1 & 25,9 & 26,2 & 26,2 & 27,5 \\
\hline Volume $\left(\mathrm{m}^{3} \mathrm{ha}^{-1}\right)$ & 235,5 & 275,2 & 291,4 & 323,9 & 342,1 \\
\hline Famílias botânicas & 43 & 43 & 43 & 42 & 42 \\
\hline Gêneros botânicos & 100 & 98 & 99 & 99 & 103 \\
\hline Espécies identificadas & 136 & 135 & 137 & 135 & 148 \\
\hline Espécies não identificadas & 4 & 3 & 4 & 3 & 5 \\
\hline Número de fustes (ha) & 1521 & 1540 & 1497 & 1474 & 1492 \\
\hline Densidade (árvores ha-1) & 1379 & 1383 & 1331 & 1307 & 1326 \\
\hline Índice de Shannon-Weaver $\left(\mathrm{H}^{\prime}\right)$ & 4,07 & 4,02 & 4,00 & 3,96 & 4,02 \\
\hline Número de indivíduos ingressos (ha)* & - & 114 & 79 & 57 & 134 \\
\hline Número de indivíduos mortos (ha)* & - & 95 & 122 & 80 & 115 \\
\hline
\end{tabular}

*Refere-se ao número de indivíduos ingressos / mortos desde a medição imediatamente anterior 
O conjunto de dados foi dividido aleatoriamente em dois grupos, com restrições de representatividade da variabilidade dos dados em cada grupo. O primeiro refere-se aos dados para treinamento de redes neurais artificiais para a projeção do dap, Ht e Hf, composto por seis parcelas, totalizando 3.556 casos nas cinco medições. O segundo refere-se aos dados para generalização das redes, composto por quatro parcelas, o que correspondeu a 2.062 casos.

A generalização consiste na capacidade de uma rede neural produzir saídas adequadas para entradas que não estavam presentes durante o treinamento, ou seja, na aprendizagem.

\section{Índices de competição para a projeção do dap, altura total e altura do fuste}

Para cada fuste (unidade básica do estudo), em cada medição, foram calculados dois índices de competição semi-independentes da distância (ISD), selecionados em estudos preliminares para a estimativa do crescimento em diâmetro (ISD $)_{d}$ ) crescimento em altura $\left(I_{S D}\right)$ (Castro, 2012). A seguir é apresentada a relação funcional dos índices de competição selecionados (Eq. 1 e 2):

$$
\begin{gathered}
I S D_{d}=\frac{H t_{i}}{\overline{H t}_{n}} \\
I S D_{h}=\frac{A S_{i}^{2}}{A S q^{2}}
\end{gathered}
$$

em que: $H t_{\mathrm{i}}=$ altura total do fuste da árvore-objeto $(\mathrm{m}) ; \overline{H t}_{n}=$ altura média dos fustes de $n$ árvores próximas da árvore-objeto $(\mathrm{m})$, limitadas a um raio de competição de seis metros; $A S_{\mathrm{i}}=$ área seccional do fuste da árvore-objeto, medido a 1,30 $\mathrm{m}\left(\mathrm{m}^{2}\right), A S q=$ área seccional correspondente ao diâmetro médio $(\mathrm{q})$ dos fustes das árvores vizinhas $\left(\mathrm{m}^{2}\right)$.

\section{Treinamento das redes neurais artificiais para projeção do dap, altura total e altura do fuste}

$\mathrm{Na}$ construção e treinamento das redes neurais, utilizou-se o software Statistica 10.0 (Statsoft Inc., 2012), sendo testadas diferentes arquiteturas de redes MLP (Multilayer Perceptron) e RBF (Radial Basis Function).

Para as redes MLP, foram avaliadas combinações de quatro diferentes funções de ativação nas camadas intermediária (apenas uma) e de saída (identidade, logística, tangencial e exponencial). Para as redes RBF, os neurônios da camada de saída foram sempre lineares (função identidade) e os neurônios da camada intermediária, função de base radial (gaussiana) como função de ativação. Foram estabelecidas um limite máximo de 200 neurônios na camada intermediária.

As redes foram treinadas para projetar o diâmetro (dap), a altura total $(H t)$ e a altura do fuste $(H f)$ como variáveis de saída, simultaneamente. Pela aplicação desta técnica, deseja-se a aproximação de uma função desconhecida $f(x)$, que descreva o mapeamento dos pares de entrada(x)-saida(y), de um conjunto de $n$ padrões de treinamento (Haykin, 2001; Binoti, 2010), sendo $x$ as variáveis independentes quantitativas e qualitativas e $y$ as variáveis quantitativas dependentes.

Os treinamentos foram do tipo feedforward, pelo método supervisionado, e as variáveis de entrada foram selecionadas na possível relação com as variáveis de saída analisadas. Foram treinadas um total de 800 arquiteturas, conforme especificado na Tabela 3. A variável "nome científico" (espécie) não foi utilizada como variável de entrada, para que as redes adquirissem maior poder generalista, ou seja, não seriam eficientes para projetarem o crescimento apenas daquelas espécies presentes no treinamento. Isso se deve ao fato de existirem espécies que ocorreram apenas um indivíduo na área. 
Tabela 3. Variáveis utilizadas no treinamento das RNA para projeção do dap, altura total (Ht) e altura do fuste $(H f)$ de árvores individuais em uma Floresta Estacional Semidecidual Montana, em estágio médio de sucessão, localizada em Viçosa - Minas Gerais

\begin{tabular}{|c|c|c|c|c|}
\hline $\begin{array}{l}\text { Número } \\
\text { da Rede }\end{array}$ & Tipo & Saídas & $\begin{array}{l}\text { Entradas } \\
\text { Numéricas }\end{array}$ & $\begin{array}{c}\text { Entradas } \\
\text { Categóricas }\end{array}$ \\
\hline 1 a 400 & MLP & $\operatorname{dap}_{2}, H t_{2}, H f_{2}$ & $\mathrm{~A}_{1}, \mathrm{~A}_{2}, \operatorname{dap}_{1}, H t_{1}, H f_{1}, \mathrm{ISD}_{\mathrm{d}}, \mathrm{ISD}_{\mathrm{h}}$ & $\mathrm{F}, \mathrm{GE}, \mathrm{C}, \mathrm{IC}, \mathrm{QC}$ \\
\hline 401 a 800 & RBF & $\mathrm{dap}_{2}, H t_{2}, H f_{2}$ & $\mathrm{~A}_{1}, \mathrm{~A}_{2}, \operatorname{dap}_{1}, H t_{1}, H f_{1}, \mathrm{ISD}_{\mathrm{d}}, \mathrm{ISD}_{\mathrm{h}}$ & $\mathrm{F}, \mathrm{GE}, \mathrm{C}, \mathrm{IC}, \mathrm{QC}$ \\
\hline
\end{tabular}

em que MLP são redes Multilayer Perceptron e RBF, redes Radial Basis Function; dap 1 e dap 2 são os diâmetros a 1,3 m (cm) atual e futuro, respectivamente; $H t_{1}$ e $H t_{2}$ são as alturas total (m) atual e futura, respectivamente; $H f_{1}$ e $H f_{2}$ são as alturas dos fustes $(m)$ atual e futura, respectivamente; $A_{1}$ e $A_{2}$ são os anos de medição atuais e futuros, respectivamente; ISD e ISDh são índices de competição semi-dependentes da distância; F é a família botânica do indivíduo; GE é o grupo ecológico; C é o nível de infestação por cipó; IC é o nível de iluminação da copa e QC é o nível de qualidade da copa.

\section{Avaliação das redes neurais artificiais para projeção do dap, altura total e altura do fuste}

Após os treinamentos, foram selecionadas as cinco melhores arquiteturas dos tipos MLP e cinco RBF, com base no coeficiente de correlação $\left(r_{\hat{v} v}\right)$ entre os valores observados e estimados de diâmetro, altura total e do fuste e na raiz do erro quadrado médio (RMSE). Quanto maior o coeficiente de correlação (próximo a 1) e menor RMSE, melhor a previsão da estimative (Eq. 3 e 4).

$$
r_{\hat{y} y}=\frac{\operatorname{cov}(Y, \hat{Y})}{\sqrt{S^{2}(Y) S^{2}(\hat{Y})}}
$$

$\operatorname{RMSE}(\%)=100 \cdot \sqrt{\frac{\sum_{i=1}^{n}(Y i-\hat{Y} i)^{2}}{n}} / \bar{Y}$

em que: $Y_{i}$ é a variável de saída observada; $\hat{Y}_{i}$ é a variável de saída estimada; cov é a covariância; $S^{2}$ é a variância; $n$ é o número total de dados; $\bar{Y}$ é a média da saída observada.

Em seguida, para avaliar o poder de generalização das redes selecionadas, foram utilizados os dados das parcelas independentes que não estavam presentes durante o treinamento. As projeções foram realizadas para a medição imediatamente posterior, ou seja, de 1994 para 1997; de 1997 para 2000; de 2000 para 2004 e de 2004 para 2008. A aplicação das redes treinadas aos dados de generalização foi feita pelo software Statistica 10.0.

Também foram calculados os valores de $r_{\hat{y} y}$ e RMSE para os dados de generalização. Além disso, foram elaborados gráficos de dispersão entre os valores observados e estimados para cada rede para as variáveis de crescimento, tanto para os dados de treinamento quanto de generalização, bem como histogramas de erros percentuais. Os erros percentuais foram calculados de acordo com a Equação 5.

$$
\operatorname{Erro}(\%)=\frac{\hat{Y}-Y}{Y} .100
$$

em que: Y é a variável de saída observada; $\hat{Y}$ é a variável de saída estimada pela rede.

\section{RESULTADOS E DISCUSSÃO}

O grupo ecológico das pioneiras apresentou maiores taxas de crescimento para as três variáveis analisadas. Maiores taxas de crescimento foram verificadas para as árvores com nenhuma infestação por cipós ou apenas cipó no tronco para dap e Ht. Entretanto, a presença de cipós não influenciou as taxas de crescimento em $\mathrm{Hf}$. O nível de iluminação das copas e a 
qualidade das copas foram os fatores que mais influenciaram as taxas de crescimento das variáveis, principalmente em dap e Ht. Árvores com iluminação total das copas e com boa qualidade das copas foram as que mais cresceram (Figura 1).

(a)
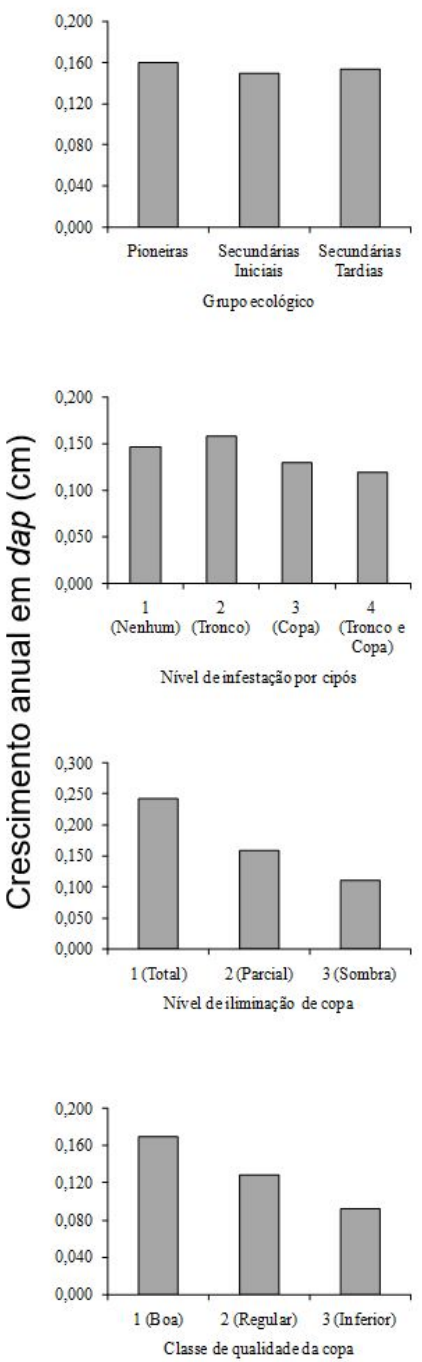

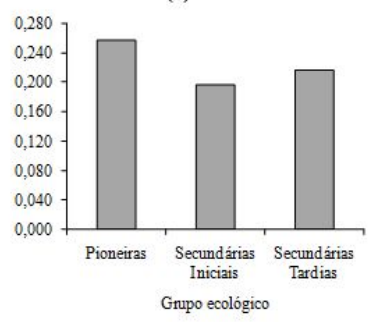

(b)

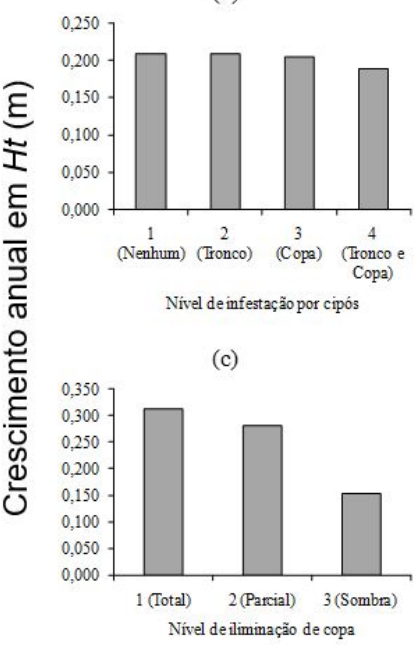

(d)

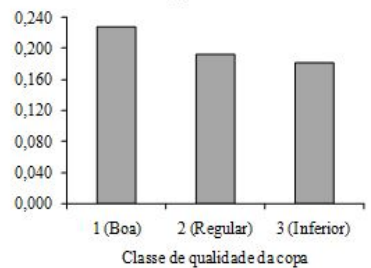

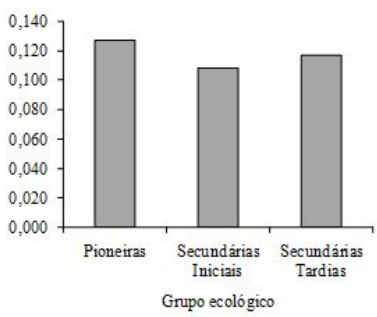
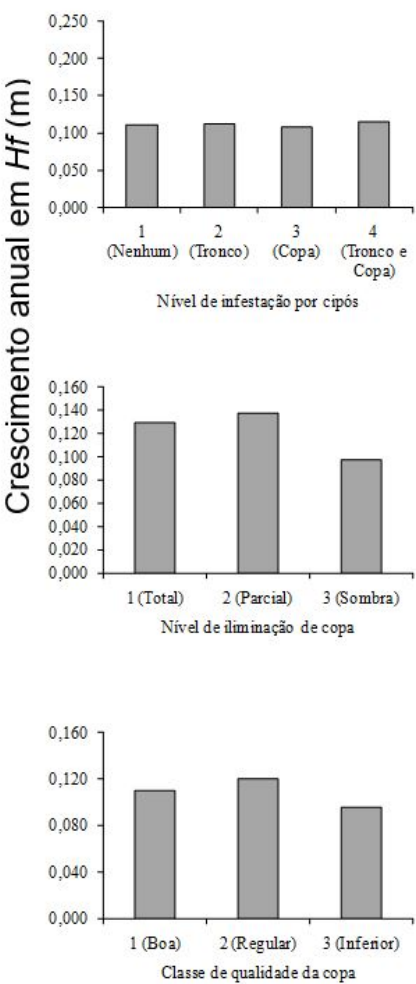

Figura 1. Efeito das variáveis qualitativas: grupo ecológico (a), nível de infestação por cipós (b), iluminação de copas (c) e qualidade da copa (d) no crescimento anual de dap, altura total ( $H t$ ) e altura do fuste $(H f)$ de árvores individuais em uma Floresta Estacional Semidecidual Montana em estágio médio de sucessão ecológica.

Todas as redes selecionadas no treinamento para projeção do diâmetro, altura total e altura do fuste, simultaneamente, apresentaram correlações maiores que 0,900, que indica alta precisão entre as estimativas e os valores reais das variáveis analisadas. Observou-se melhor poder de generalização das redes MLP, que apresentaram simultaneamente, maiores valores de $r_{\hat{y y y}}$ e menores valores de RMSE para as três variáveis (Tabela 4). 
Tabela 4. Resumo das redes neurais artificiais selecionadas para a projeção simultânea das variáveis dap, altura total $(H t)$ e altura do fuste $(H f)$ de árvores individuais em uma Floresta Estacional Semidecidual Montana em estágio médio de sucessão, localizada em Viçosa - Minas Gerais

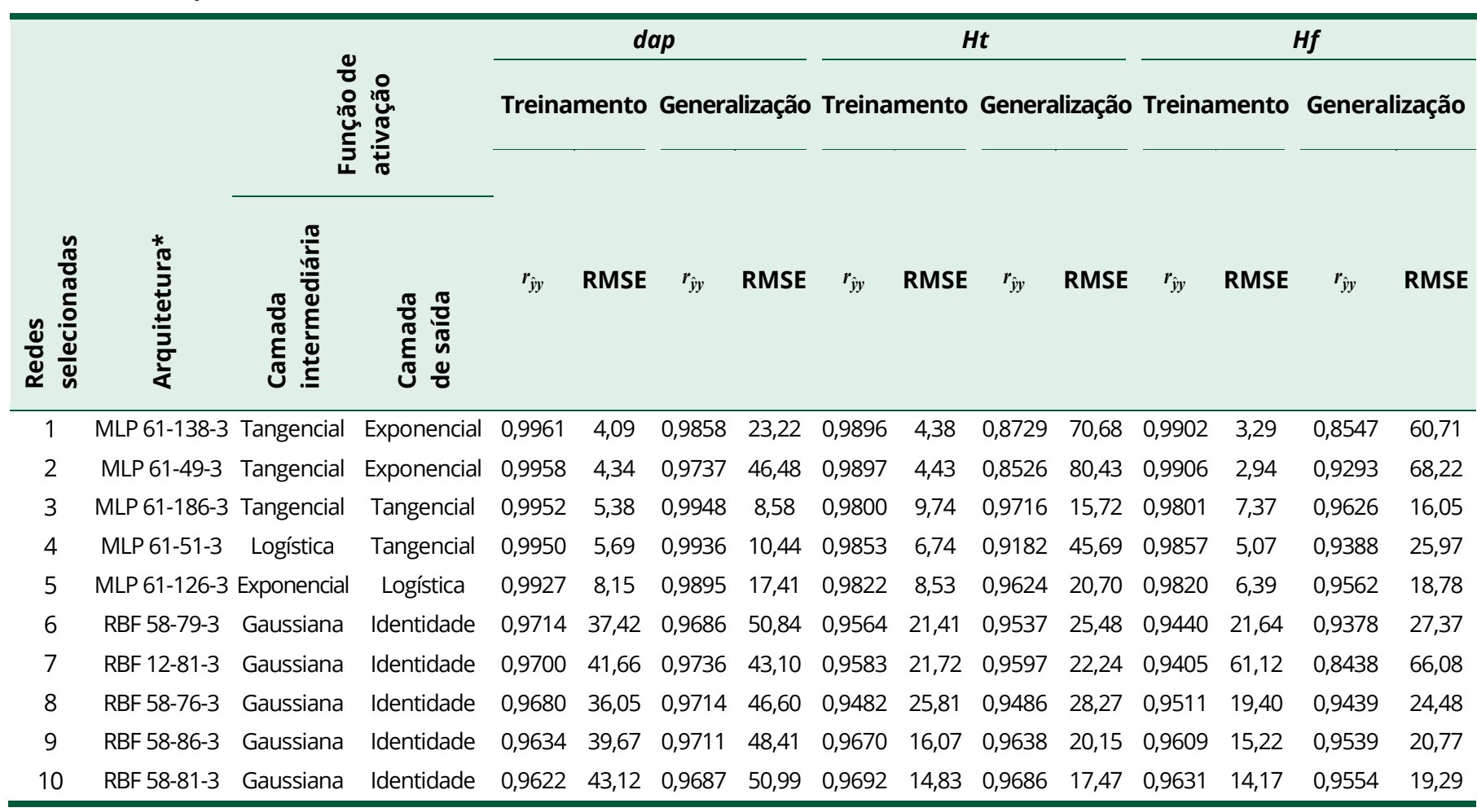

Em que MLP são redes Multilayer Perceptron e RBF, redes Radial Basis Function; ( $\left.{ }^{\star}\right)$ indica o número de neurônios da camada de entrada, intermediária e saída, respectivamente. As redes $\mathrm{RBF}$ 6, 8, 9 e 10 não utilizaram a variável de entrada QC. A rede 7 não utilizou as variáveis de entrada $\mathrm{A}_{2}$, F, C, IC e $H f_{1}$.

Para o dap, as redes MLP apresentaram coeficientes de correlação entre os valores observados e estimados $\left(r_{\hat{y y y}}\right)$ maiores que 0,990 no treinamento, e para as redes RBF, entre 0,960 e 0,980. Valores de RMSE inferiores a 9\% foram observados para as redes MLP, enquanto que para as redes RBF eles foram superiores a 35\% (Tabela 4).

Todas as redes foram acuradas para projeção do diâmetro das árvores individuais, indicando alta eficiência do método. Os valores de $r_{\hat{y} y}$ na generalização foram superiores a 0,970 para as redes MLP e para as redes RBF, entre 0,960 e 0,980. Em relação à RMSE, observou-se que as redes MLP apresentaram valores entre $8 \%$ e $23 \%$, enquanto as redes RBF apresentaram valores superiores a $40 \%$ (Tabela 4).

Para a variável $H t$, as redes MLP apresentaram coeficientes de correlação maiores que 0,980 para o treinamento, e entre 0,940 e 0,970 para as redes RBF. Em relação à RMSE, observou-se que as redes MLP apresentaram valores inferiores a $10 \%$, enquanto as redes RBF apresentaram valores superiores a $14 \%$.

Ao avaliar o poder de generalização das redes selecionadas, observou-se que todas foram acuradas para a projeção da altura total das árvores individuais, com valores de $r_{\hat{y} y}$ superiores a 0,850 para as redes MLP e 0,940 para as redes RBF.

$\mathrm{Na}$ análise da variável $H f$, observou-se que as redes MLP apresentaram coeficientes de correlação entre os valores observados e estimados $\left(r_{\hat{y y y}}\right)$ maiores que 0,980 para os dados de treinamento, e entre 0,840 e 0,970 para as redes RBF. Em relação à RMSE, observou-se que as redes MLP apresentaram valores inferiores a $8 \%$, enquanto as redes RBF apresentaram valores entre $14 \%$ e $62 \%$ (Tabela 4).

A rede 3 (MLP) apresentou melhor desempenho para estimar, simultaneamente o dap, a altura total e a altura do fuste. Esta rede concentrou 186 neurônios na única camada intermediária, utilizando funções de ativação tangencial nos neurônios das camadas intermediária e saída. 
Embora não tenha apresentado as melhores estatísticas durante o treinamento para a variável dap (Tabela 4), a rede 3 obteve a melhor precisão em relação aos dados de generalização, para todas as variáveis.

As estimativas em relação aos valores observados ficaram próximas à linha $45^{\circ}$ entre os valores observados e estimados e concentrando os erros percentuais mais próximos à zero. Pode-se constatar que parte das redes, apesar de apresentarem um bom desempenho durante o treinamento, não adquirem a capacidade de generalização com a mesma eficiência devido à um possível sub ou supertreinamento (Figura 2, 3, 4).
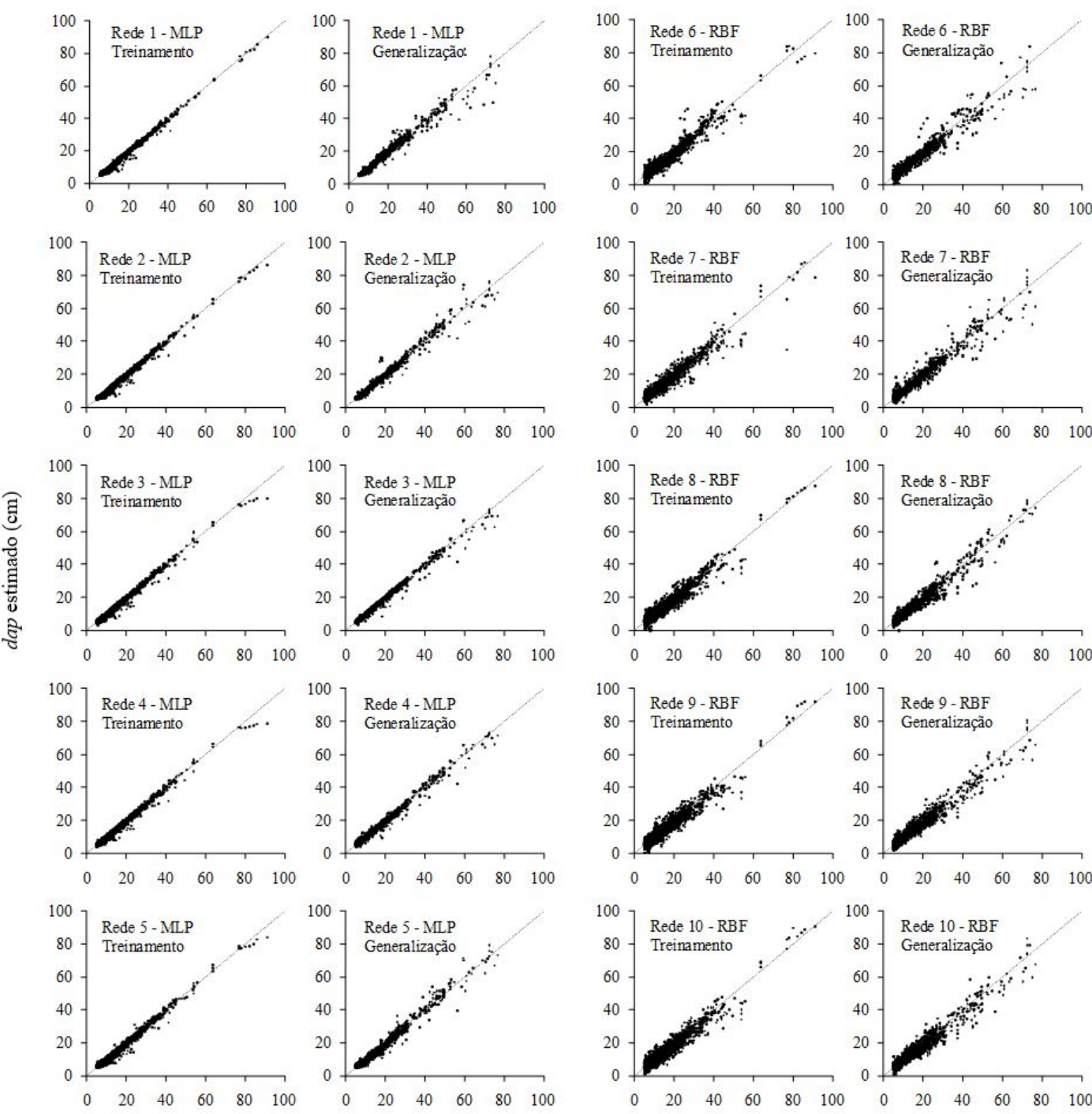

dap observado $(\mathrm{cm})$

Figura 2. Diâmetros a 1,3 m de altura (dap) observado e estimado por redes neurais artificiais para os dados de treinamento e generalização. 

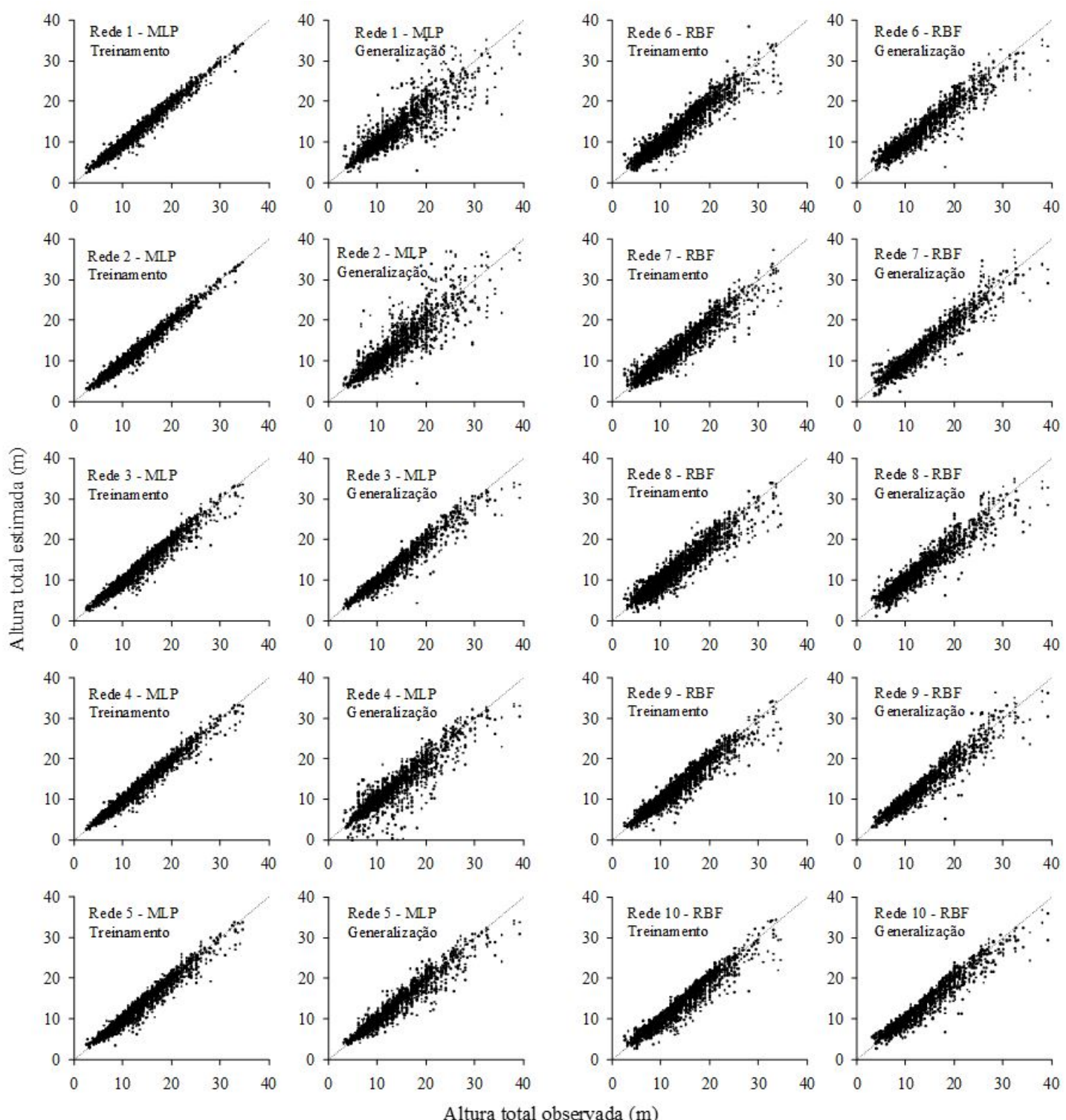

Figura 3. Altura total $(H t)$ observada e estimada por redes neurais artificiais para os dados de treinamento e generalização. 

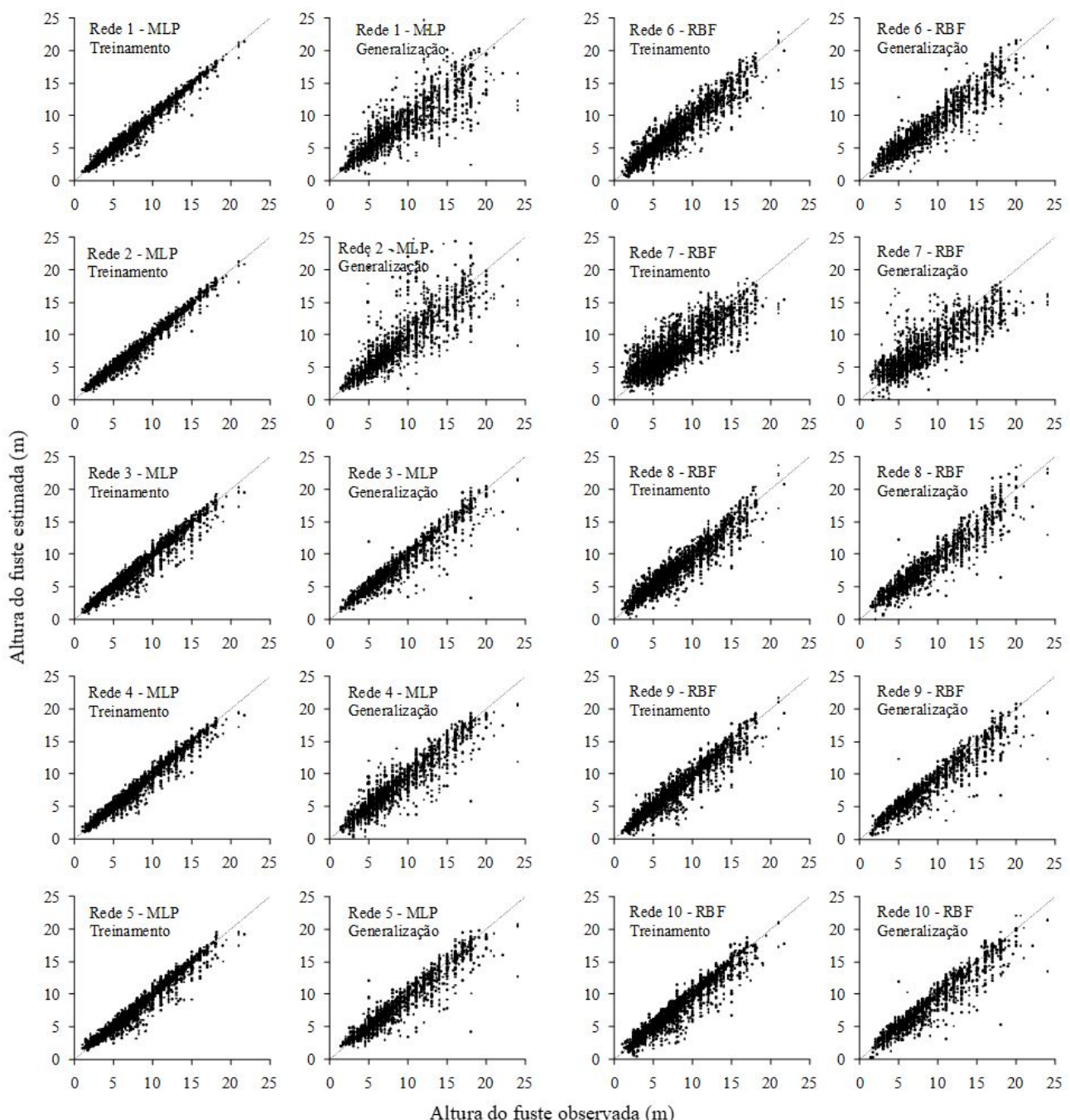

Figura 4. Altura do fuste $(H f)$ observada e estimada por redes neurais artificiais para os dados de treinamento e generalização.

O uso de metodologias que associam variáveis qualitativas na análise de crescimento das árvores e dos povoamentos é uma prática já utilizada em países com tradição no manejo florestal (Silva, 2007), entretanto, não são utilizados em modelos de crescimento e produção no Brasil. A agregação dessas informações qualitativas pode aumentar o entendimento sobre o crescimento das florestas. Assim, se torna fundamental o levantamento dessas variáveis qualitativas durante os inventários florestais, para subsidiar os estudos de ecologia e modelagem das florestas.

Porras (2007) obteve sucesso no treinamento de RNA's com função de ativação tangencial nos neurônios das camadas intermediárias e função linear na camada de saída para projeção do diâmetro e altura de Pinus cooperi em uma floresta do México, utilizando índices independentes da distância. Após aplicação das RNA's aos dados de generalização foram observados valores de $r_{\hat{y} y}$ superiores a 0,900 para a projeção do dap e 0,950 para altura total.

Binoti (2010) obteve valores de $r_{\hat{y} y}$ superiores a 0,980 e RMSE inferiores a $4 \%$ no treinamento de redes neurais Perceptron (Linear), MLP e RBF para diâmetro e altura de eucaliptos em diferentes condições de crescimento, sem o uso de índices de competição como variáveis entrada. Após aplicação das redes aos dados de generalização, foram observados valores superiores a 0,970 de $r_{\hat{y} y}$ e RMSE inferiores a 5\% para ambas as variáveis.

Castro (2011) verificou eficiência de redes neurais do tipo MLP para projeção do diâmetro e altura de árvores em florestas comerciais de eucalipto da região norte do Brasil. As melhores RNA's apresentaram valores de $r_{\hat{y} y}$ superiores a 0,980 e raiz quadrada do erro médio inferiores 
a $1 \%$ no treinamento das redes. Após a validação do seu modelo, foram encontradas estimativas superiores a 0,900 de $r_{\hat{y y}}$ e RQEM inferiores a $2 \%$ para as duas variáveis.

Utilizando modelos de regressão, Adame et al. (2008) encontraram estimativas de $r_{\hat{y} y}$ entre 0,509 e 0,540, após ajustes para crescimento em diâmetro de Eucalyptus globulus. Soares \& Tomé (1997) encontraram estimativas superiores a 0,90 de $r_{\hat{y y}}$ para Eucalyptus globulus. Martins (2011) obteve coeficientes de correlação entre 0,980 e 0,990 em modelos para projeção do diâmetro e altura de eucalipto em diferentes classes de produtividade na região norte do Brasil. Mette et al. (2009) obtiveram estimativas de $r_{\hat{y y y}}$ entre 0,670 e 0,930 para Picea glauca utilizando diferentes equações de crescimento em altura.

Verifica-se que não existe a necessidade de se treinar uma rede para cada variável, visto que a precisão atingiu as expectativas de projeção, sendo essa mais uma vantagem do uso de redes neurais artificiais na modelagem do crescimento em nível de árvores individuais.

Mesmo se tratando de uma floresta com elevada heterogeneidade de espécies, com árvores de diferentes idades, taxas de crescimento e sanidade, a projeção obtida neste estudo em nível de árvore foi eficiente. Assim, as RNA's têm grande potencial de uso na modelagem do crescimento de árvores em florestas naturais no Brasil.

\section{CONCLUSÃO}

Redes neurais artificiais são eficientes para projetar o diâmetro e a altura de árvores individuais em florestas inequiâneas.

Uma única rede neural estima de modo eficiente o dap, altura total e altura do fuste, simultaneamente.

A rede selecionada foi uma MLP com 186 neurônios na camada intermediária e funções tangenciais em todos os neurônios.

\section{REFERÊNCIAS}

Adame, P., Hynynen, J., Cañellas, I., \& Del Río, M. (2008). Individual-tree diameter growth model for rebollo oak (Quercus pyrenaica Willd.) coppices. Forest Ecology and Management, 255(3-4), 1011-1022. http://dx.doi.org/10.1016/j.foreco.2007.10.019.

Andreassen, K., \& Tomter, S. M. (2003). Basal area growth models for individual trees of norway spruce, scots pine, birch and broadleaves in Norway. Forest Ecology and Management, 180(1-3), 11-24. http://dx.doi.org/10.1016/S0378-1127(02)00560-1.

Barreto, J. M. (2002). Introdução às redes neurais artificiais (57р.). Florianópolis: UFSC.

Bella, I. E. (1971). A new competition model for individual tree. Forest Science, 17(3), 364-372.

Binoti, M. L. M. S. (2010). Redes neurais artificiais para prognose da produção de povoamentos não desbastados de eucalipto (Dissertação de mestrado). Universidade Federal de Viçosa, Viçosa.

Braga, A. P., Carvalho, A. P. L. F., \& Ludemir, T. B. (2000). Redes neurais artificiais: teoria e aplicações. Rio de Janeiro: Editora LTC.

Castro, R. V. O. (2011). Modelagem do crescimento em nível de árvores individuais utilizando redes neurais e autômatos celulares (Dissertação de mestrado). Universidade Federal de Viçosa, Viçosa.

Castro, R. V. O. (2012). Modelagem de árvore individual para uma Floresta Estacional Semidecidual utilizando redes neurais (Tese de doutorado). Universidade Federal de Viçosa, Viçosa.

Cunha, A. C. M. C. M. (2010). Diagnose nutricional de minicepas e previsão de enraizamento de miniestacas de eucalipto por redes neurais artificiais (Tese de doutorado). Universidade Federal de Viçosa, Viçosa.

Daniels, R. F. (1976). Simple competition indices and their correlation with annual loblolly pine tree growth. Forest Science, 22(4), 454-456.

Diamantopoulou, M. J. (2005). Artificial neural networks as an alternative tool in pine bark volume estimation. Computers and Electronics in Agriculture, 48(3), 235-244. http://dx.doi.org/10.1016/j.compag.2005.04.002.

Eid, T., \& Tuhus, E. (2001). Models for individual tree mortality in Norway. Forest Ecology and Management, 154(1), 69-84. http://dx.doi.org/10.1016/S0378-1127(00)00634-4. 
Gandolfi, S., Leitão-Filho, H. F., \& Bezerra, C. L. (1995). Levantamento florístico e caráter sucessional de espécies arbustivo-arbóreas de uma floresta Mesófila Semidecidua no município de Guarulhos, SP. Revista Brasileira de Biologia, 55(4), 753-767.

Glover, G. R., \& Hool, J. N. (1979). A basal area ratio predictor of loblolly pine plantation mortality. Forest Science, 25(2), 275-282.

Guan, B. T., \& Gertner, G. (1991). Modeling red pine tree survival with an artificial neural network. Forest Science, 37, 1429-1440.

Hasenauer, H., \& Monserud, R. A. (1996). A crow model for Austrian species. Forest Ecology and Management, 84(1-3), 49-60. http://dx.doi.org/10.1016/0378-1127(96)03768-1.

Hasenauer, H., Monserud, R. A., \& Gregoire, T. G. (1998). Using simultaneous regression techniques with individual-tree growth models. Forest Science, 44, 87-95.

Haykin, S. (2001). Redes neurais: princípios e prática (2. ed., 900 p). Porto Alegre: Bookman.

Jain, A. K., Jianchang Mao, \& Mohiuddin, K. M. (1996). Artificial neural networks: a tutorial. Computer, 29(3), 31-44. http://dx.doi.org/10.1109/2.485891.

Martins, F. B. (2011). Modelagem de crescimento em nível de árvore individual para plantios comerciais de eucalipto (Tese de doutorado). Universidade Federal de Viçosa, Viçosa.

Mette, T., Albrecht, A., Ammer, O., Biber, P., Kohnle, U., \& Pretzsch, H. (2009). Evaluation of the forest growth simulator SILVA on dominant trees in mature mixed silver fir - norway spruce stands in south west Germany. Ecological Modelling, 220(13-14), 1670-1680. http://dx.doi.org/10.1016/j.ecolmodel.2009.03.018.

Miehle, P., Battaglia, M., Sands, P. J., Forrester, D. I., Feikema, P. M., Livesley, S. J., Morris, J. D., \& Arndt, S. K. (2009). A comparison of four process-based models and a statistical regression model to predict growth of Eucalyptus globules plantations. Ecological Modelling, 220, 734-746. http://dx.doi.org/10.1016/j.ecolmodel.2008.12.010.

Özçelik, R., Diamantopoulou, M. J., Brooks, J. R., \& Wiant Junior, H. V. (2010). Estimating tree bole volume using artificial neural network models for four species in Turkey. Journal of Environmental Management, 91(3), 742-753. http://dx.doi.org/10.1016/j.jenvman.2009.10.002. PMid:19880241.

Porras, J. C. (2007). Growth evaluation of a conifer forest (Pinus Cooperí Blanco) using a neural net backpropagation trained with distance independent competition measures. Computación y Sistemas, 10(4), 415-427.

Sánchez-González, M., Río, M., Cañellas, I., \& Montero, G. (2006). Distance independent tree diameter growth model for cork oak stands. Forest Ecology and Management, 255(1), 262-270. http://dx.doi.org/10.1016/j.foreco.2006.01.002.

Silva, J. N. M., \& Lopes, J. C. A. (1984). Inventário florestal contínuo em florestas tropicais: a metodologia utilizada pela Embrapa-Cpatu na Amazônia brasileira (Documentos, 36, 36 p.). Belém: Embrapa-CPATU.

Silva, L. T. M. (2007). Morfometria, qualidade do tronco e da copa de Peltophorum dubium (Spreng.) Taub. em povoamento experimental no estado do Rio Grande do Sul (Dissertação de mestrado). Universidade Federal de Santa Maria, Santa Maria.

Soares, P., \& Tomé, M. (1997). A distance dependent diameter growth model for first rotation eucalyptus plantation in Portugal, In A. Amaro \& M. Tomé, (Eds), Empirical and process - bases models for forest tree and stand growth simulation ( p.267-270). Lisboa: Salamandra.

Statsoft Inc. (2012). Statistica (data analysis software system), version 10.0. Tulsa: Statsoft Inc.

Tomé, M., \& Burkhart, H. E. (1989). Distance-dependent competition measures for predicting growth of individual tree. Forest Science, 35(3), 816-831.

Vospernik, S., Monserud, R. A., \& Sterba, H. (2010). Do individual tree growth models correctly represent height: diameter ratios of Norway spruce and scots pine? Forest Ecology and Management, 260(10), 1735-1753. http://dx.doi.org/10.1016/j.foreco.2010.07.055. PMid:21151352.

Contribuição dos Autores: RVOC: conceituação, análise formal, obtenção de financiamento, investigação, metodologia, administração do projeto, supervisão, validação, escrita - primeira redação; CPBS: conceituação, curadoria dos dados, investigação, metodologia, administração do projeto, supervisão, escrita - revisão e edição; HGL: conceituação, investigação, metodologia, supervisão, escrita - revisão e edição; ALS: conceituação, curadoria dos dados, investigação, metodologia, escrita - revisão e edição; FBM: metodologia, escrita - revisão e edição; GSN: escrita - revisão e edição, MLRO: escrita - revisão e edição. 